\title{
CREATIVITY AS NEOLIBERAL SELF-GOVERNANCE
}

\author{
Jakub BARSZCZEWSKI (10 ${ }^{*}$ \\ Institute of Sociology, University of Białystok, Plac NZS 1, 15-420 Białystok, Poland
}

Received 23 March 2020; accepted 26 July 2021

\begin{abstract}
The purpose of this article is to analyze the problem of non-professional creativity in contemporary self-help literature. Creativity, an element of work organization in the post-Fordist era, has been the subject of many critical analyses. I focus on creativity as it appears in everyday life, with the support of an examination of self-help handbooks that refer to far-east traditions, at the same time being critical of the Western lifestyle. Self-help literature is viewed here as a tool aiding the neoliberal governmentality of society. I am most of all interested in how contemporary discourse on non-professional creativity promotes technologies of autonomy aimed at the production of responsible and self-sufficient individuals. I argue that creativity is today a key mechanism of governance. It is not limited to the professional sphere but is playing an increasing role in our private lives. It is used to produce more elusive and flexible forms of self-governance than more openly repressive forms of power (based on top-down order and control).
\end{abstract}

Keywords: creativity, governmentality, neoliberalism, post-Fordism, self-help literature.

\section{Introduction}

In recent decades, creativity as an element of work organization in our post-Fordist age has been the subject of many critical analyses. Luc Boltanski and Eve Chiapello have studied this issue in their comprehensive analysis of post-Fordist work organization - The New Spirit of Capitalism (2005, originally published in 1999). Creativity (along with other organizational principles of post-Fordist enterprises such as innovation-based production, flexible specialization, communication-based management, knowledge-based work, flexible working hours, group work or the flat hierarchy) is one of the most important ways contemporary capitalism can be legitimated. On the one hand, creativity represents an alternative to the bureaucratic organization of life under Fordism and transforms work into something that can provide selffulfilment. On the other hand, it can serve to justify new inequalities and deprive employees of the achievements of the Fordist era (e.g. temporary employment, self-development as a duty rather than a choice, the absence of a division between work and leisure) (Boltanski \& Chiapello, 2005, pp. 441-449).

\footnotetext{
*Corresponding author. E-mail: j.barszczewski@uwb.edu.pl
} 
Other authors have pointed out that the concept of creativity is far from being a normatively neutral term. It is promoted within the educational system as a desirable trait, a necessary competency of the entrepreneurial and innovative individual (Kalin, 2016). In this it has been viewed as an ideological veil, a façade hiding the fact of increasingly precarious employment conditions (Mould, 2018). Creativity also appears in critical analyses of management discourse. Craig Prichard argues that the discourse of creativity encourages employees to constantly develop professional competence. As a consequence, the boundary between the professional sphere and leisure time becomes blurred (Prichard, 2002). Creativity has come to be understood not as a spontaneous, potentially subversive activity, but rather as an attitude towards individual self-development and the realization of instrumental values (Townley, 1995). Getz and Robinson (2003) point out that creativity focused on innovation distracts attention from the high failure rates of innovative ventures. Korean researchers have shown that in Asia, after the 1997 Asian financial crisis, the discourse of creativity was supposed to help redefine the role of the worker (as an individualized and self-improving subject). Creative activity is not limited to the professional sphere, but also extends to one's private life (as a domain of "autotelic creativity"). They also have argued that management science is interested in the sphere of free time as a place for developing the creative abilities that are required at work (Yoon et al., 2019).

This article examines how non-professional creativity is entangled in the mechanisms of power. It begins with the characteristics of the concept of neoliberal governmentality and the current state of research in this area. In the further part of the text, I present the problem of technologies of autonomy and how it manifests itself in the self-help literature. I argue that selfhelp handbooks support formation of autonomous subjects whose aspirations would be in line with the expectations of modern power. Further, I describe connections between the concept of technologies of autonomy and the idea of non-professional creativity, which is presented in self-help handbooks as a source of self-fulfilment and well-being. In the last part of the article, I analyze a few self-help handbooks in order to demonstrate how non-professional creativity may be converted into technology of autonomy and a subtle mechanism of disciplining.

\section{Neoliberal governmentality and creativity}

In this section, I analyze the concept of creativity as an element of neoliberal governmentality. In Michel Foucault's conception, neoliberal governmentality is highly decentralized power. Its purpose is the stimulation of economic rationality and a rational ordering of society. Neoliberal governmentality clearly distinguishes itself from disciplinary power (which is in turn interested in top-down discipline, training and the enforcement of appropriate behaviour). Neoliberalism encourages the individual to act rationally and make utilitarian choices both in the economic and non-economic sphere. The neoliberal subject is not simply a liberal homo economicus whose market choices are based on a calculation of profit and loss. The market paradigm is extended to the whole of society thereby becoming a model for all interpersonal relationships. All actions are subject to economic calculation and the concept of capital is no longer limited to the sphere of production and material exchange. Every individual becomes the owner of capital: innate traits and acquired competencies that can be developed 
and multiplied through thoughtful investment (e.g. in relations, in education or in health). So, everyday life consists of many possible choices that can multiply one's embodied capital. The individual becomes an "entrepreneur of themselves". Both their relationships with others and with their own body require an economic approach, rational choices. Neoliberal governmentality is an extremely devious kind of power, because it transforms governance into self-governance. It invokes the rationality of the ruled. Unlike conventional forms of power, which supervise and enforce obedience, it provides individuals with a wide range of freedoms, encouraging them towards self-care, to making rational investments and developing their own capital (Foucault, 2010, pp. 219-226, 252-253).

In recent years, many researchers have analysed the influence of neoliberal governmentality (in self-help books, talk-shows, positive psychology, etc.) (Binkley, 2011; Erjavec \& Volčič, 2009; Hazleden, 2003; Matza, 2012; Tie, 2004). The neoliberal self is presented as a form of identity oriented towards entrepreneurial activities. It represents individualism, the pursuit of profit and a utilitarian conception of nature as a resource (Fernández-Herrería \& Martínez-Rodríguez, 2016, p. 4).

Critical analyses of related conceptions of creativity have described it primarily as a profit-driven competency that is supposed to ensure success in professional sphere. It is also supposed to have been deprived of its subversive potential, being reduced to the domain of commodified ideas and normalizing ever greater involvement in professional life (at the expense of private life).

In this article I am interested in creativity as a non-professional activity and the incorporation of art into everyday life focused on self-creation. In contrast to the aforementioned authors, I am interested in how the contemporary discourse of non-professional creativity is entangled in the mechanisms of neoliberal governmentality.

Following Foucault, I assume in this article that neoliberalism is an order oriented towards the formation of enterprising individuals interested in maximizing their non-economic capital. It is not an ideology that is limited to the economy; it is a form of power that treats individual as an object of investments and aims at the individualization of social risk.

My analysis is based on the case of self-help guides that draw on Far Eastern traditions. I have focussed on this kind of literature because its message seems subversive. These handbooks criticize a consumerist and workaholic society, at the same time stimulating the reader to undertake specific, potentially liberating, practices. They are therefore a source of a particularly challenging discourse: it questions the certain values as harmful and proposes an alternative vision of the "healthy" individual.

I argue that the non-Western traditions presented in self-help guides offer the vision of a subject that coincides with the mechanisms of neoliberal governmentality. These books promote the idea of an individual who is responsible for his or her own autonomy and, through self-care, protects themselves from threats to this autonomy (manifested in society).

The article aims to show how non-professional creativity supports the production of neoliberal, autonomous subjects. Why the creative attitude and practices presented in the selfhelp literature may be interpreted as a source of subtle forms of disciplining individuals? I am also interested in how non-professional creativity can be reconciled with self-management techniques and converted into instrumental practice? 
The article fills out existing critical analyses of the role of creativity in professional life by showing that non-professional creativity is also entangled in the mechanisms of neoliberal governmentality. Non-Western approaches to creativity do not offer alternatives to the problems of Western society (materialism, consumerism, workaholism, etc.). They only call for a proper transformation of one's own subjectivity in order to achieve a more flexible, balanced, economic attitude. However, the underlying instrumental imperatives are still there - hiding behind self-creation practices.

I analyze three self-help guides (Kintsugi: The Japanese Art of Embracing the Imperfect and Loving Your Flaws (Navarro, 2019), Awakening Your Ikigai: How the Japanese Wake Up to Joy and Purpose Every Day (Mogi, 2018), L'art de la Liste: Simplify, Organise, Enrich Your Life (Loreau, 2018)). Finally, I also refer to Western self-development handbooks which transform the idea of self-creation into something closer to the instrumental management of everyday life (The Bullet Journal Method: Track the Past, Order the Present, Design the Future (Carroll, 2018)).

The analysis of the self-help handbooks aims to demonstrate how non-professional creativity is presented and understood by their authors. In particular, I focus on (wrong) views and attitudes which are criticized in these texts. What is the unique value of creativity (as an alternative to the attitudes and views criticized by the authors)? The analysis of the "liberatory" potential of non-professional creativity presented in the texts allows to reveal its disciplining function.

\section{Technologies of autonomy and self-help literature}

Nikolas Rose has developed Foucault's concept of neoliberal governmentality by arguing that technologies of autonomy are mechanisms that form responsible and self-sufficient individuals. Psychology and psychotherapy have played a key role in developing these technologies of autonomy. In Rose's view, they have not only sought to help individuals with existential problems but have stimulated disciplined self-control.

The technologies of autonomy rely on two main mechanisms. Firstly, a subjectification of work that aims to transform work into the object of individual care and self-fulfilment. Secondly, it involves a psychologization of the mundane, transforming everyday problems into subjective constraints to be thought over and overcome. The aim of these technologies of autonomy is to stimulate the individual to undertake systematic reflection and self-development to transform themselves into responsible and rational subjects. Rose argues that technologies of autonomy correspond to existing political rationales that expect individuals to strive for self-improvement as subjects capable of competing in the market (1999, pp. 244-246, 258).

Heidi Marie Rimke argues that self-help guides are a tool to form a subject that exhibits certain desirable characteristics from the point of view of modern power (a subject that is governable, predictable, classifiable, self-conscious and self-determined). Experts direct individuals to follow specific prescriptions and view themselves as self-steering and capable of shaping their lives. The individual in question is transformed into a self-governing subject capable of self-fulfilment within the framework of "freedom" (existing norms and institutions) (Rimke, 2000, p. 72). I here continue the analysis of self-help handbooks as examples of technologies of autonomy and am particularly interested in the role of non-professional creativity and the incorporation of art into everyday life. 


\section{Kintsugi}

The handbook Kintsugi by Navarro (2019) accuses contemporary Western society of a destructive cult of competition and an unhealthy pursuit of success. It points out that excessive praise of insensitivity has become serious problem, because it makes people helpless in the face of the adversities they face in life - their reactions to real or imagined problems tends to be exaggerated and have a destructive effect on their lives.

The author argues that in place of hopeless resistance to growing problems, we should aim to rebuild ourselves after adversities strike and then learn from our experiences. $\mathrm{He}$ proposes the idea of universal curiosity and compassion instead of a constant distrust and a sense of threat.

In this context he invokes kintsugi, the Japanese art of repairing broken pottery which, after reconstruction, becomes even more beautiful than before. According to Navarro, emotional wounds are not entirely beyond the control of the individual. We have to take charge, care for them and adopt a rational approach to adversity as something palpable and possible to overcome. If we do not, we will always end up destroying ourselves:

"Why don't we heal our emotional wounds? Why do we close our eyes and ignore what our soul is begging us to see? [...] In some cases we have become disconnected from our emotional strength and the resources available to cope with adversity. [...] Sometimes we have lost perspective, and we deceive ourselves with the pain that we feel. Some people have internalized the idea that we have come to this world to suffer, and for that reason, do nothing to stop their suffering" (Navarro, 2019, pp. 22-23).

The art of kintsugi is a metaphor for a mature approach to pain and suffering. We have to learn to transform bad experiences into valuable knowledge about ourselves and reality to be able to make wounds beautiful. Practicing this art allows us to rationally order emotional wounds. It is a way of distancing ourselves from suffering, thereby becoming aware of the available options and adopting a more emotionally balanced approach to life. Reflecting on our own suffering not only frees ourselves from its negative impact, it is also a valuable experience that will help us in future struggles:

"Art is as varied and diverse as the artist can be. Paint, draw, sew, design, or create. [...] Write. Writing is one of the most therapeutic exercises you can undertake, for a number of reasons. To begin with, when you write, you are putting into order all your ideas, preoccupations, and troubles. Writing frees up the soul and the mind. [...] Build. Go to the beach with a bucket and spade, and start making sand sculptures. [...] Do some sculpture, design clothes, make your own dresses, or dye T-shirts. Anything will do! Do whatever you feel like, as long as you find it stimulating and fulfilling. Find an outlet for your pain through artistic expression. Transform your pain into something beautiful. Embellish your scars so that every time you look at them you feel stronger and more confident" (Navarro, 2019, p. 42).

However, this handbook is not a philosophical analysis of suffering as a universal human problem. Losing a job is treated here like a number of other existential problems (such as dealing with the loss of love, hope or joy) - i.e. as a matter requiring deep reflection and a reconciliation with fate. The author defines this problem in terms of individual emotional maturity (to quit a deeply unsatisfactory job, to accept the precarity of employment and transform passions into professional activity). A non-professional practice of art is thereby invoked 
to shape a distanced approach to uncertainty (the ability to reduce and reinterpret suffering), to improve individual reflection and to encourage flexible adaptation to changing conditions.

\title{
4. Ikigai
}

Awakening Your Ikigai by Mogi (2018), is a book showing the value of Japanese traditions that ensure a long, healthy and happy life. Japan is presented here as the very opposite of Western society. Unlike the Western world - based on individualism, endless competition and the mindless pursuit of new technologies - Japan remains a country that respects tradition, community values, sophisticated rituals (such as tea ceremonies) and autotelic work (even after retirement). The principles of ikigai are a counterweight for societies based on rush (versus "being in the here and now"), consumerism ("the joy of little things"), selfishness ("harmony and sustainability") and stress ("releasing yourself”):

\begin{abstract}
"Needless to say, a value system centered on just the top few cannot be sustained, because somebody has got to be the underdog in order for someone to be at the top. In today's world, where humans are increasingly forced to compete in a global context, we need to consider the implications and repercussions of this obsession with winning the competition. A mindset with the drive to win can lead to great innovations. The same mindset can also lead to excessive stress and instability, both for individuals and society" (Mogi, 2018, p. 124).
\end{abstract}

Non-professional creativity is a kind of rebellion against the instrumental values of Western society. It develops mental resilience in the face of a lack of external gratification and it helps readers to adopt an autotelic approach to their daily activities. It is also a tool for acquiring self-discipline and increasing one's awareness that life is full of coincidence and uncertainty. Thanks to creativity, we can develop a new attitude to our work, which will recognize the need for autotelic dimension of our activity (previously dominated by maximization of productivity and profit):

"In life, we sometimes misplace priorities and significance. Too often, we do something for the sake of rewards [...]. In general, there are delays between actions and rewards. Even if you finish a good work, rewards are not necessarily forthcoming: Reception and recognition occur in a stochastic way, depending on many parameters out of your control. If you can make the process of making the effort your primary source of happiness, then you have succeeded in the most important challenge of your life. So make music, even when nobody is listening. Draw a picture, when nobody is watching. Write a short story that no one will read. The inner joys and satisfaction will be more than enough to make you carry on with your life. If you have succeeded in doing so, then you have made yourself a master of being in the here and now" (Mogi, 2018, pp. 106-107).

Overcoming workaholism through creativity seems to be about perfecting one's adaptability and this art involves moving beyond a conception of ourselves in terms of victory or defeat. According to ikigai, life's everyday activities should be continuous process of work seeking joy and fulfilment, in that way just like amateur creative activity - doing certain things because we attain inner satisfaction regardless of other people's opinions. Happiness here becomes a subjective ability to transform instrumental obligations into autotelic aspirations that can lead to a sense of satisfaction: 


\begin{abstract}
"What have we learned? That ikigai is an adaptation to the environment, no matter what the nature of that environment might be. From sumo to classical ballet, people who find ikigai can find joys beyond the simplistic value of wins and losses. Having ikigai contributes toward making the very best of circumstances, which might otherwise be difficult - regardless of the fact they might be difficult. [...] Most crucially, you cannot and should not blame the environment for a lack of ikigai" (Mogi, 2018, p. 151).
\end{abstract}

The idea of practicing non-professional creativity represents a criticism of the lifestyle of Western societies, yet it does not question the basic tenets of a capitalism based on individualism and market competition. The philosophy of ikigai asks us to appreciate the spiritual dimension of our existence. It requires us to develop a reflexive approach in the face of an everyday life that is filled with instrumental goals. The emphasis on the role of community and harmony is related to the need for greater self-control and an overcoming of an unhealthy pursuit of success. However, this change of emphasis serves primarily to develop self-discipline and independence from external conditions (which represent a threat to individual's autonomy). Ultimately ikigai's values strengthen individualistic attitudes that pursue individual happiness.

\title{
5. L'art de la Liste
}

The book Lart de la Liste was written by the French essayist Dominique Loreau who lives in Japan. She suggests that Far Eastern traditions can help in achieving a more balanced organization of our lives. Her book can be located among other non-Western guides to minimalism - a very popular genre in the Western world in recent years (e.g. Kondo, 2014). However, Lart de la Liste is not just about simple living and a radical limitation of one's possessions. Loreau argues that the art of a simpler life is not only about limiting one's consumption. It also means incorporating art into everyday life. She is critical of the commercialization of the idea of self-help and the transformation of the art of counselling into an incomprehensible cacophony of opinions. The contemporary counselling industry in publishing encourages a meaningless life of hurry, preventing its readers from discovering the truth about themselves:

\begin{abstract}
"Self-help books continue to flood the marketplace, offering methods and techniques to help you become your best possible self. And all, in some way, recommend taking notes and making lists. Many different voices are vying for our attention - and we may be interested in many of them - but we cannot gain a deep understanding of all these techniques. We hope that the next magazine we buy, the next book we read, will offer us a better, easier, quicker approach [...]. So we plough on with our reading, tirelessly striving to find the latest 'secret' miracle for losing weight or destressing, for finding happiness or our very own Prince Charming” (Loreau, 2018, p. 5).
\end{abstract}

Loreau argues that the practice of making lists can be a tool for self-analysis. Lists are used to improve purely instrumental activities, which, thanks to meticulous planning of tasks, allow you to simplify everyday activities or better organize your time. Thus, they are an excellent tool making one's life more economical (for instance with time-saving lists). According to the author, this "economization" should transform itself into rituals and not a top-down orders. Transforming everyday tasks into rituals ensures greater inner balance as well as efficiency in performing those tasks: 
"The mere fact of stopping time, of giving yourself permission to be lazy, allows you to rediscover the relativity of time, to feel the flow of it, without being controlled by it. Sometimes rituals can help. They help you to concentrate, to focus your attention, to sweep the mental cobwebs away. They help you to banish your internal tensions and find yourself again. [...] They help you to move between tasks seamlessly. [...] Plan your priorities for the week. [...] Do the housework on Saturday" (Loreau, 2018, p. 17).

However, lists offer a much more complex range of possibilities: they can become a tool to completely transform our subjectivity and life. The first step in this process is self-knowledge, finding out the truth about ourselves. Making lists can be a form of dialogue with your own body and allows one to connect with one's physicality:

"Lists allow us to discover the psychological causes of illnesses, and even change the course of them. Making a list of conversations to have with your body will help you to understand the role we play in catching illnesses. Our bodies send us messages when they are in need of attention. Noticing and listening to these messages helps us to take action to overcome health problems. All these signals are trying to do is rouse us from our passivity, from the lack of responsibility we are taking for our bodies" (Loreau, 2018, p. 32).

The next stage is a detailed self-analysis to reveal our fears, limitations and unfulfilled desires. The therapeutic function of lists can help deal with difficult emotions and overcome barriers that limit our development:

"What is love? What is success? What is happiness? What unique gift do you have to offer others? By committing a description of yourself to paper, and being able to refer to it, you will feel more 'yourself'. You will become surer in your choices and decisions; your actions will be more considered. We can find more meaning in life if we act according to our own values, so it is important to define our values" (Loreau, 2018, p. 48).

And the function of lists goes beyond this purely therapeutic dimension. Along with deeper and deeper penetration into ourselves, highly personal experiences and unique sensory experiences start to emerge. Everyday activities in this way begin to resemble artistic activity. Meticulous reflection on our favourite tastes (objects, songs, moments, books, etc.) leads to a conscious experience of even the most trivial experiences, something that can enrich our everyday life and transform our existence into a work of art:

"This may come as a surprise, but a good number of people do not know their own tastes. If you ask them their favourite colour or their favourite style of interior design, they'll give you a random answer, something that doesn't reflect them. [...] But according to image consultant, knowing your favourite colour, and living in it, will make you more successful. You'll feel more yourself, more engaged, more resolute. Living this way will give you a better sense of mental harmony" (Loreau, 2018, p. 89).

Making lists turns the individual into a reflective subject able to harmoniously rationalize their life through everyday creativity. Managing everyday life is transformed into creative work; self-discipline results from self-knowing. Everyday life filled with non-professional creativity is a space for developing internal harmony and, at the same time, for perfecting instrumental competencies such as self-confidence, effectiveness and an economic approach to life. 


\section{The bullet journal method}

The above criticisms of Western society and the idea of engaging creativity to restore individual autonomy can also be found in Western self-help handbooks. One such is Ryder Carroll's The Bullet Journal Method (2018), which shows the reader how to create a bullet journal (a planner which combines the functions of calendar, journal, sketchbook, and to-do list). It is aimed at a comprehensive reorganization of everyday life striving for greater autonomy, authenticity and personal agency. Bullet journal is not limited to specific therapeutic practices or self-improvement but outlines a systematic program to transform all aspects of life (including everyday tasks, career, free time, health, spirituality, etc.). Its structure clearly differs from the ordinary calendar (limited as the latter is to collecting important dates and deadlines). It consists of user-designed modules (e.g. tasks, schedules, notebooks), which allow for deeper self-reflection as well as planning (features and aspects include a daily log, experiences, challenges, past and future events). The idea of bullet journal stems from the perception that we fail in the pursuit of happiness because of the goal of maximizing pleasure. This in turn is the result of a lack of self-reflection and a lack of awareness of personal needs:

"Think back to the last goal you achieved. You pushed yourself hard, drawn by the po-
tential and promise of happier life. But when you finally crossed the finish line, what
did you find? Did that rise, that new house, that car, that vacation, make you feel the
way you hoped it would? [...] As we race toward our goals, we learn new things, and
our circumstances change. By the time we arrive at the finish line, we're simply dif-
ferent people. The best we can do is guess what will make us happy. So we place blind
bets, gambling away our money, our time, and our sanity in the pursuit of happiness"
(Carroll, 2018, pp. 141-142).

Bullet journal is a response to problems that are typical of late capitalist societies: information overload, lack of time, perfectionism, the ineffectiveness of self-help literature (incapable of showing how to translate aspirations and beliefs into action) and a resulting inability to attain self-knowledge. In contrast to the top-down prescriptions of self-help handbooks, bullet journal helps the user discover the truth about themselves. This in turn allows them to increase their own agency and awareness of their actual needs. The artisan nature of bullet journal plays a key role: the user does not simply buy another product, a set of fixed (limited) functions, but designs their own tool, shaping and adjusting it to their own needs. Manual work and handwriting serve to encourage greater reflection and clearer thinking:

\footnotetext{
"Writing by hand helps us think and feel simultaneously. [...] When we write by hand, we're forced to be more economical and strategic with our use of language, crafting notes in our own words. To do that, we have to listen more closely, think about the information, and essentially distil others' word and thoughts through our own neurological filtration system and onto the page. Typing notes, in contrast, can quickly become rote: a frictionless highway where information freely passes in one ear and right out the other" (Carroll, 2018, p. 47).
}

Self-expression is also an act of working on oneself. Thanks to the artisan approach to planning, users distance themselves from the world and become more honest with themselves. Daily creative practice (as opposed to merely ticking off tasks) mobilizes one to make written content more functional and legible. It provokes questions going beyond the realm 
of everyday life: What really interests me and how can my curiosity be realized? In this way we are able to focus more, set clearer goals, be more self-disciplined and self-tracking:

\begin{abstract}
"Appropriating other people's goals is another common pitfall. [...] Your goals need real substance in order to be sustainable. You need to understand exactly why you need million dollars. Your goals should be inspired by your felt experience. Surely you have sources of real passion in your life - whether the positive impetus of what brings you joy or painful lessons from the school of hard knocks. Put them to work! Both are powerful wells from which you can draw meaningful goals" (Carroll, 2018, p. 150).
\end{abstract}

Bullet journal discredits the inauthentic messaging of self-development guides. It offers instead an individualized program of self-fulfilment based on balanced, measurable and wellthought-out goals (the result of reflection and small steps). However, this is not limited to the question of effectiveness. Thanks to bullet journal, everyday life is fulfilled with a regular habit of introspection and repetitive duties are transformed into new sustainable routines. Along with a new approach to planning there is a perceived need for a more efficient, economic and self-reflective approach focused on individual development. It seeks not only to increase personal agency, but authentic self-fulfilment - the result of a deep rethinking of individual aspirations and their subsequent incorporation into daily action plans.

\title{
Conclusions
}

This article has presented self-help guides as a source of technologies of autonomy. They criticize Western society, suggesting the potential of non-professional creativity and the incorporation of art into everyday life. These handbooks advocate creative activity as an alternative to contemporary problems (consumerism, workaholism, etc.). Their authors, however, do not question the legitimacy of the general assumptions of neoliberal capitalism. They are only interested in combating threats to individual autonomy (e.g. lack of agency, mental limitations, inhibitions). These technologies of autonomy are intended to discredit attitudes that have prevented individual from functioning as efficient subjects in professional and everyday life (i.e. as satisfied, flexible, hard-working, etc. people). In this way repressive orders, expressed through the idea of non-professional creativity, have gained a more subtle and non-repressive character. Shaping the subject through technologies of autonomy has been presented in selfhelp guides as a defence of the individual in the face of an inauthentic and repressive society. Creative activity can also be used to construct more comprehensive self-management tools that do not rely solely on specific therapeutic practices. The idea of a bullet journal (a planner tailored to individual needs) is a synthesis of therapeutic practices and the economic function of non-professional creativity - a combination of instrumental planning, self-reflection and self-fulfilment. Designing a bullet journal is a non-professional creative activity that stimulates greater self-discipline and productivity, without resorting to repressive dictates. It provides a basis for the overall transformation of the individual into an "entrepreneur of themselves" - one who is interested in individual self-improvement and human capital maximization (for example, increasing their mental resilience, self-control and scrupulousness). The handbooks considered are an example of individualized mechanisms of neoliberal governmentality, which guide the individual towards the responsible development of their own abilities, to economic self-sufficiency and emotional maturity. These technologies of 
autonomy encourage the individual to develop their responsible self-governance and to act as a self-steering subject - in both everyday and professional life.

\section{References}

Binkley, S. (2011). Happiness, positive psychology and the program of Neoliberal governmentality. Subjectivity, 4(4), 371-394. https://doi.org/10.1057/sub.2011.16

Boltanski, L., \& Chiapello, E. (2005). The new spirit of Capitalism. Verso. https://doi.org/10.1007/s10767-006-9006-9

Carroll, R. (2018). The bullet journal method: Track the past, order the present, design the future. Portfolio/Penguin.

Erjavec, K., \& Volčič, Z. (2009). Management through Spiritual Self-Help Discourse in Post-Socialist Slovenia. Discourse and Communication, 3(2), 123-143. https://doi.org/10.1177/1750481309102449

Fernández-Herrería, A., \& Martínez-Rodríguez, F. M. (2016). Deconstructing the Neoliberal "Entrepreneurial Self": A critical perspective derived from a global "Biophilic Consciousness". Policy Futures in Education, 14(3), 314-326. https://doi.org/10.1177/1478210316631709

Foucault, M. (2010). The birth of biopolitics: Lectures at the Collège de France, 1978-1979. Picador.

Getz, I., \& Robinson, A. G. (2003). Innovate or die: Is that a fact? Creativity and Innovation Management, 12(3), 130-136. https://doi.org/10.1111/1467-8691.00276

Hazleden, R. (2003). Love Yourself: The relationship of the self with itself in popular self-help texts. Journal of Sociology, 39(4), 413-428. https://doi.org/10.1177/0004869003394006

Kalin, N. M. (2016). We're all creatives now: Democratized creativity and education. Journal of the Canadian Association for Curriculum Studies, 13(2), 32-44.

Kondo, M. (2014). The life-changing magic of tidying: A simple, effective way to banish clutter forever. Vermilion.

Loreau, D. (2018). L'art de la Liste: Simplify, organise, enrich your life. Trapeze.

Matza, T. (2012). Moscow's echo: Technologies of the self, publics, and politics on the Russian talk show. Cultural Anthropology, 24(3), 489-522. https://doi.org/10.1111/j.1548-1360.2009.01038.x

Mogi, K. (2018). Awakening Your Ikigai: How the Japanese wake up to joy and purpose every day. The Experiment.

Mould, O. (2018). Against creativity. Verso.

Navarro, T. (2019). Kintsugi: The Japanese art of embracing the imperfect and loving your flaws. Sounds True.

Prichard, C. (2002). Creative selves? Critically reading "Creativity" in management discourse. Creativity and Innovation Management, 11(4), 265-276. https://doi.org/10.1111/1467-8691.00258

Rimke, H. M. (2000). Governing citizens through self-help literature. Cultural Studies, 14(1), 61-78. https://doi.org/10.1080/095023800334986

Rose, N. (1999). Governing the soul: The shaping of the private self. Free Association Books.

Tie, W. (2004). The psychic life of governmentality. Culture, Theory and Critique, 45(2), 161-176. https://doi.org/10.1080/1473578042000283844

Townley, B. (1995). "Know Thyself": Self-awareness, self-formation and managing. Organization, 2(2), 271-289. https://doi.org/10.1177/135050849522010

Yoon, S. J., Chae, Y. J., Yang, K., \& Kim, H. (2019). Governing through creativity: Discursive formation and Neoliberal subjectivity in Korean firms. Organization, 26(2), 175-198.

https://doi.org/10.1177/1350508418805286 